\title{
Polyploid Mosaics Induced by Temperature Shocks in the Giant Freshwater Prawns Macrobrachium rosenbergii
}

\author{
Praneet Damrongphol* and Pleanphit Jaroensastraraks
}

Department of Biology, Faculty of Science, Mahidol University, Bangkok 10400, Thailand

Accepted March 6, 2001

\begin{abstract}
Summary Cold shocks at $10^{\circ} \mathrm{C}, 12^{\circ} \mathrm{C}, 15^{\circ} \mathrm{C}$ and heat shocks at $32^{\circ} \mathrm{C}, 35^{\circ} \mathrm{C}$ or $38^{\circ} \mathrm{C}$ were administered to $4 \mathrm{~h}$ - or $6 \mathrm{~h}$-fertilized eggs of the giant freshwater prawns, Macrobrachium rosenbergii, for a period of $4 \mathrm{~h}$ or $6 \mathrm{~h}$. The treated eggs were further cultured in vitro at room temperature $\left(29^{\circ} \mathrm{C}\right)$. The control was in vitro cultured at room temperature to hatching. Both cold and heat shocks caused an abnormal chromosome separation resulting in a formation of fused nuclei. Mosaics, individuals containing both diploid and polyploid cells, rather than complete polyploids were induced. Cold shocks at $10^{\circ} \mathrm{C}$ were detrimental while at $15^{\circ} \mathrm{C}$ were inefficient. Whereas application of $12^{\circ} \mathrm{C}$ to $4 \mathrm{~h}$-fertilized eggs for $6 \mathrm{~h}$ or to $6 \mathrm{~h}$-fertilized eggs for $4 \mathrm{~h}$ produced polyploid mosaics and enlarged embryos but caused great reduction in the survival rates. Heat shocks at $32^{\circ} \mathrm{C}$ did not induce mosaicism or enlarged embryo, while at $38^{\circ} \mathrm{C}$ were detrimental. Application of $35^{\circ} \mathrm{C}$ to $4 \mathrm{~h}$-fertilized eggs for a long duration of $6 \mathrm{~h}$ or to $6 \mathrm{~h}$-fertilized eggs for $4 \mathrm{~h}$ produced some mosaics and enlarged embryos. Though, enlarged embryos appeared to develop normally and survived to the hatching days (18-19 days), none engaged in hatching. Defect in the hatching enzymes upon the treatments was suggested. Key words Temperature shocks, Mosaic, Chromosome segregation, Prawn, Macrobrachium rosenbergii.
\end{abstract}

Chromosome manipulation of embryos by temperature shocks or by chemical treatments with cytochalasin B has been accomplished in a number of species of fish (Lemoine and Smith 1980, Refstie 1981, Wolters et al. 1981, Lincoln and Scott 1983, Johnston 1985, Arai and Wilkins 1987) and shellfish (Quillet and Panelay 1986, Yamamoto and Sugawara 1988, Beaumont and Contairis 1988, Beaumont and Fairbrother 1991, Guo et al. 1992a, b). Application of treatments at an appropriate time prevents polar body separation during meiosis or prevents separation of a dividing cell producing a triploid or a tetraploid embryo respectively.

A triploid organism is reproductively sterile due to the failure of homologous chromosomes pairing during meiosis and is expected to have an increased growth rate due to reduced gonad development. However, a tetraploid organism is normally fertile but acquires a larger body size than a diploid counterpart.

It is of interest to investigate the possibility of inducing polyploidy in the giant freshwater prawns, Macrobrachium rosenbergii. Successful attempt could have great economic advantage in prawn culture. This paper reports the results on an attempt to manipulate chromosome number in the giant freshwater prawn, $M$. rosenbergii, by temperature shocks.

\section{Materials and methods}

Sexually mature giant freshwater prawns, $M$. rosenbergii were laboratory maintained as previously described (Damrongphol et al. 1991a). Mating and oviposition were allowed under laboratory conditions. Fertilized eggs were collected at 4 and $6 \mathrm{~h}$ after oviposition from the abdomens of the

\footnotetext{
* Corresponding author, e-mail: scpdr@mahidol.ac.th
} 
females. About 300 eggs were placed in each $100 \mathrm{ml}$ evaporating dish containing about $50 \mathrm{ml}$ of $15 \%(\mathrm{v} / \mathrm{v})$ artificial seawater (ASW). The evaporating dishes were placed in circulating baths set at various temperatures, $10^{\circ} \mathrm{C}, 12^{\circ} \mathrm{C}, 15^{\circ} \mathrm{C}, 32^{\circ} \mathrm{C} 35^{\circ} \mathrm{C}$ or $38^{\circ} \mathrm{C}$. The eggs were subjected to various temperature shocks for 4 or $6 \mathrm{~h}$. After temperature shocks, the embryos were in vitro cultured further in $15 \% \mathrm{ASW}$ at room temperature $\left(29^{\circ} \mathrm{C}\right)$ to hatching according to the method described by Damrongphol et al. (1990). The control eggs were in vitro cultured to hatching at room temperature after collecting from the abdomens of the females at $4 \mathrm{~h}$ after oviposition. Fresh $15 \%$ ASW was replaced every 2-3 days. Survivals and development of the embryos were examined periodically. Hatching normally occurred on day 18-19 after oviposition. Survival rate (number of surviving embryos/total number of embryos) and percentage of enlarged embryos (number of enlarged embryos/surviving embryos) were determined on day 16. For chromosome analysis, samples of the controls and the treated eggs at 6 and $24 \mathrm{~h}$ after oviposition were fixed in ethanol: acetic acid $(3: 1)$ for $24 \mathrm{~h}$ and stained with $1 \%$ aceto-orcein for $15 \mathrm{~min}$. The stained specimens were washed briefly with $45 \%$ acetic acid and covered with cover-slip before examining with a bright-field microscope.

\section{Results}

The results from cold and heat shocks are summarized in Table 1. Three parameters, temperature, starting time and duration of treatment were monitored. The controls showed normal development. The first mitotic division occurred at about $6 \mathrm{~h}$ after oviposition (Table 1, Fig. 1). By $24 \mathrm{~h}$, the embryos contained a large number of equal-size cells. Upon staining with aceto-orcein, cytoplasm and cell boundary were not clearly seen but the equal-size nuclei and a regular nuclear interspacing were shown (Fig. 2). The survival rate of $55.3 \% \pm 7.3$ S.E. were observed on day 16 of development

Table 1. The effect of heat and cold shocks on chromosome behavior, survival and development of the embryos

\begin{tabular}{|c|c|c|c|c|c|c|}
\hline $\begin{array}{c}\text { Temperature } \\
\left({ }^{\circ} \mathrm{C}\right)\end{array}$ & $\begin{array}{c}\text { Age of } \\
\text { embryos starting } \\
\text { treatment (h after } \\
\text { oviposition) }\end{array}$ & $\begin{array}{l}\text { Duration of } \\
\text { treatment } \\
\text { (h) }\end{array}$ & $\begin{array}{l}\text { Chromosomes } \\
\text { at } 6 \mathrm{~h} \text { after } \\
\text { oviposition }\end{array}$ & $\begin{array}{c}\text { Nuclear } \\
\text { interspacing } \\
\text { at } 24 \mathrm{~h} \text { after } \\
\text { oviposition }\end{array}$ & $\begin{array}{l}\text { Survival } \\
\text { rate on } \\
\text { day } 16^{\mathrm{a}} \\
(\% \pm \text { S.E. })\end{array}$ & $\begin{array}{c}\text { Enlarged } \\
\text { embryos } \\
\text { on day } 16^{\text {a }} \\
(\% \pm \text { S.E. })\end{array}$ \\
\hline \multicolumn{7}{|l|}{ Control: } \\
\hline Room temperature & - & - & First anaphase & Regular & $55.3 \pm 7.3$ & 0 \\
\hline \multicolumn{7}{|l|}{ Cold shocks: } \\
\hline \multirow[t]{3}{*}{10} & 4 & 4 & Abnormal & Abnormal & 0 & 0 \\
\hline & & 6 & Abnormal & Abnormal & 0 & 0 \\
\hline & 6 & 4 & - & Abnormal & 0 & 0 \\
\hline \multirow[t]{3}{*}{12} & 4 & 4 & Anaphase & Regular & $36.3 \pm 5.8$ & \\
\hline & & 6 & Anaphase & Irregular & $31.8 \pm 6.2$ & $12.3 \pm 5.3$ \\
\hline & 6 & 4 & $1-$ & Irregular & $33.5 \pm 5.8$ & $23.0 \pm 8.1$ \\
\hline \multirow[t]{3}{*}{15} & 4 & 4 & Anaphase & Regular & $41.8 \pm 6.6$ & 0 \\
\hline & & 6 & Anaphase & Regular & $38.5 \pm 6.3$ & 0 \\
\hline & 6 & 4 & - & Regular & $43.0 \pm 5.8$ & 0 \\
\hline \multicolumn{7}{|l|}{ Heat shocks: } \\
\hline \multirow[t]{3}{*}{32} & 4 & 4 & Anaphase & Regular & $50.5 \pm 7.2$ & 0 \\
\hline & & 6 & Anaphase & Regular & $47.5 \pm 8.1$ & 0 \\
\hline & 6 & 4 & $1-$ & Regular & $51.3 \pm 4.1$ & 0 \\
\hline \multirow[t]{3}{*}{35} & 4 & 4 & Anaphase, 2 nuclei & Regular & $40.5 \pm 5.6$ & 0 \\
\hline & & 6 & Anaphase, 2 nuclei & Irregular & $35.8 \pm 5.7$ & $11.5 \pm 8.2$ \\
\hline & 6 & 4 & - & Irregular & $39.8 \pm 5.1$ & $9.5 \pm 7.2$ \\
\hline \multirow[t]{3}{*}{38} & 4 & 4 & Abnormal & Abnormal & 0 & 0 \\
\hline & & 6 & Abnormal & Abnormal & 0 & 0 \\
\hline & 6 & 4 & - & Abnormal & 0 & 0 \\
\hline
\end{tabular}

\footnotetext{
${ }^{\text {a }}$ Each value represents the mean of 4 different experiment \pm S.E.
} 

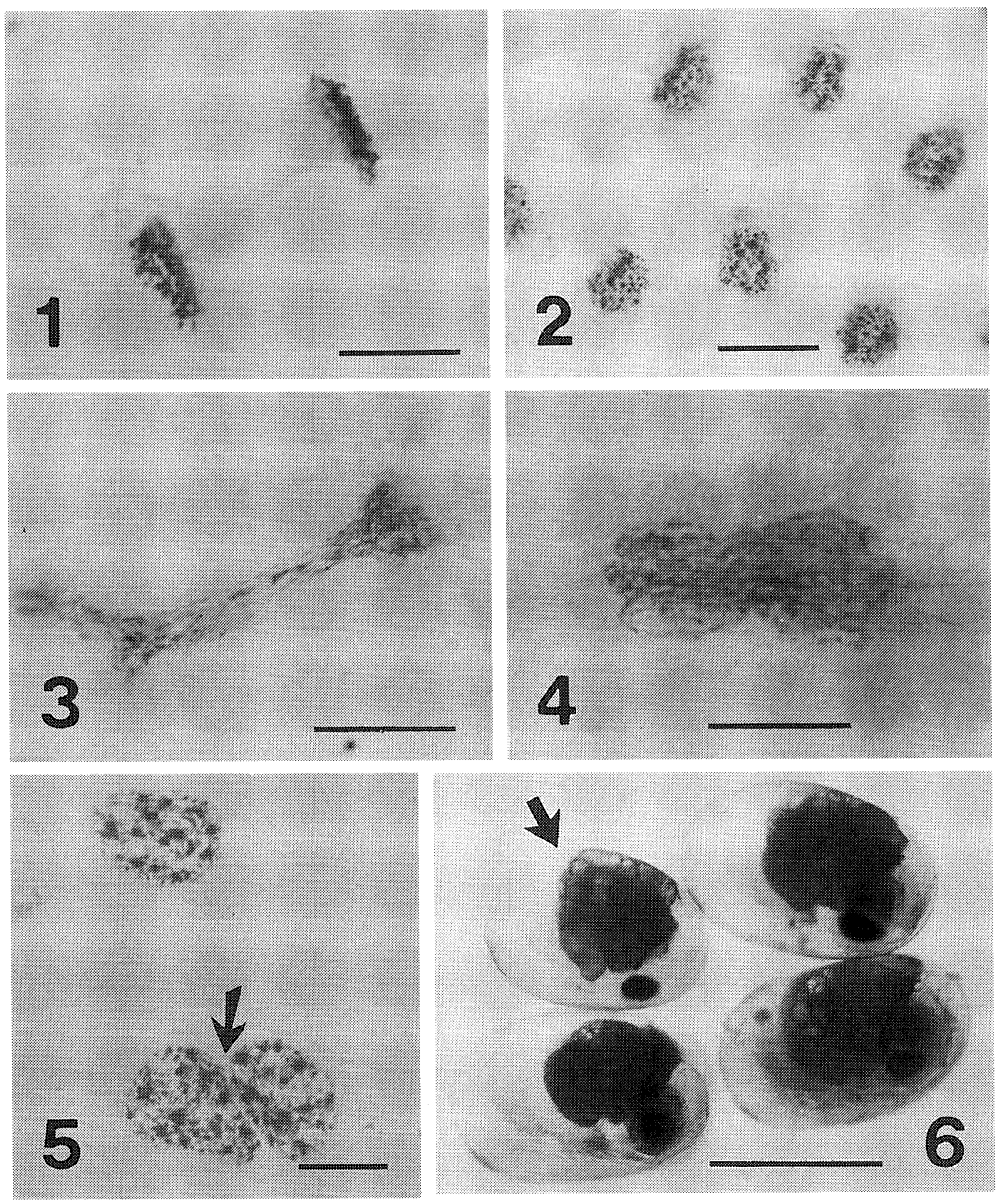

Figs. 1-6. 1) The control egg at $6 \mathrm{~h}$ after oviposition showed the first mitotic anaphase. Scale bar $=50 \mu \mathrm{m}$. 2) The control embryo at $24 \mathrm{~h}$ exhibited a regular nuclear interspacing. Scale bar $=50 \mu \mathrm{m}$. 3) The $4 \mathrm{~h}$-egg treated at $35^{\circ} \mathrm{C}$ for $4 \mathrm{~h}$ showed an abnormal chromosome separation of the first mitotic anaphase at $6 \mathrm{~h}$-after oviposition. Scale bar $=50 \mu \mathrm{m}$. 4) The $4 \mathrm{~h}$-egg treated at $35^{\circ} \mathrm{C}$ for $4 \mathrm{~h}$ showed an abnormal chromosome separation causing fusion of the 2 chromosome groups at $6 \mathrm{~h}$ after oviposition. Scale bar $=50 \mu \mathrm{m}$. 5) The $6 \mathrm{~h}$-egg treated at $12^{\circ} \mathrm{C}$ for $4 \mathrm{~h}$ showed an irregular nuclear interspacing at $24 \mathrm{~h}$ after oviposition. Fusion of 2 nuclei (arrow) was observed. Scale bar $=20 \mu \mathrm{m}$. 6) The enlarged embryos induced by application of $12^{\circ} \mathrm{C}$ to $6 \mathrm{~h}$-eggs for $4 \mathrm{~h}$ showed normal development and were about twice the size that of the normal embryo (arrow) on day 16 of development. Scale bar $=500 \mu \mathrm{m}$.

and hatching normally commenced on day 18-19.

Abnormal chromosome separation at the first mitotic division (Fig. 3) was observed in both cold and heat shocks resulting in fusion of the chromosome groups (Fig. 4). Chromosome analysis of $24 \mathrm{~h}$-embryos revealed that mosaics, individual containing both diploid and polyploid cells, rather than complete polyploids were induced. Mosaic embryos containing cells with a single nucleus and cells with fused nuclei caused an irregular interspacing between nuclei (Fig. 5).

Cold shocks of $4 \mathrm{~h}$ - or $6 \mathrm{~h}$-fertilized eggs at $10^{\circ} \mathrm{C}$ for various durations were detrimental. The chromosomal stage was halted at the time of treatment producing abnormally condensed chromosomes observed at 6 and $24 \mathrm{~h}$ after oviposition. The embryos did not survived pass day 5 of development. Cold shocks of $4 \mathrm{~h}$-eggs at $12^{\circ} \mathrm{C}$ for $4 \mathrm{~h}$ neither induced the occurrence of mosaic nor enlarged embryo. Whereas treatment for $6 \mathrm{~h}$ produced few mosaics shown by an irregular interspacing of the nuclei observed at $24 \mathrm{~h}$ and some $\left(12.3 \% \pm 5.3 \mathrm{~S}\right.$.E.) enlarged embryos. Application of $12^{\circ} \mathrm{C}$ 
to $6 \mathrm{~h}$-eggs for $4 \mathrm{~h}$ also effectively induced mosaicism and a high level (23.0\% $08.1 \mathrm{~S}$.E.) of enlarged embryos but caused a low level $(33.5 \% \pm 5.8$ S.E.) of survival rate on day 16 after oviposition. However, cold shocks at $15^{\circ} \mathrm{C}$ were not effective. Normal chromosome behavior was observed either at 6 or $24 \mathrm{~h}$ after oviposition and no enlarged embryo was found. Nevertheless, survival rates of the treated embryos were lower than that of the control (Table 1).

Heat shocks of $4 \mathrm{~h}$ - or $6 \mathrm{~h}$-fertilized eggs at $32^{\circ} \mathrm{C}$ for various durations did not cause significant alteration of the chromosomal stages. No enlarged embryo was induced and the survival rates were lower than that of the control (Table 1). Heat shocks of $4 \mathrm{~h}$-fertilized eggs at $35^{\circ} \mathrm{C}$ induced some mosaicism shown by an irregular nuclear interspacing observed at $24 \mathrm{~h}$ after oviposition. Mosaics and enlarged embryos $(11.5 \% \pm 8.2$ S.E.) were found only in those shocked for a long duration of $6 \mathrm{~h}$. Likewise mosaics and enlarged embryos $(9.5 \% \pm 7.2 \mathrm{~S}$.E.) were induced in $6 \mathrm{~h}$-fertilized eggs treated at $35^{\circ} \mathrm{C}$ for $4 \mathrm{~h}$. Heat shocks at $38^{\circ} \mathrm{C}$ was harsh; all treated groups showed low survival rates and did not survive to day 16 (Table 1).

All enlarged embryos induced by heat or cold shocks exhibited about twice the size that of the control (Fig. 6). Although they developed normally and survived to hatching day (18-19 days), none was able to hatch.

\section{Discussion}

Application of temperature shocks at an appropiate time for an appropriate duration is crucial for suppression of cytokinesis of the fertilized eggs. The starting time of treatments at 4 or $6 \mathrm{~h}$ and duration of 4 or $6 \mathrm{~h}$ of treatments were selected based on previous studies. The first mitotic metaphase or anaphase of the fertilized giant freshwater prawn eggs occurs at about $5 \mathrm{~h}$ after ovipostion; and the first and the second cytokineses occur simultaneously and are completed by $9 \mathrm{~h}$ after oviposition (Damrongphol et al. 1991b).

The present study demonstrates that both cold and heat shocks efficiently induce polyploidy in the giant freshwater prawn embryos; but the efficient temperature range is narrow. It is either too mild to be effective or too harsh for normal embryo development. However, cold shocks seem to be more effective than heat shocks in producing mosaics and enlarged embryos. The effect of temperature shocks on cytokinesis is implicated. Although abnormal chromosome separation at the first anaphase was induced causing fusion or association of the chromosome groups, termination of the shocks prior to the completion of cytokinesis, i.e. treatment of $4 \mathrm{~h}$-eggs for only $4 \mathrm{~h}$, did not effectively induce formation of mosaic or enlarged embryo. The treated eggs seem to resume normal division after further cultured at room temperature. Mosaics may be produced but with such a low number that they are not detected. While extended treatments for a long period of $6 \mathrm{~h}$ or treatments of $6 \mathrm{~h}$-eggs for $4 \mathrm{~h}$, which were terminated after the completion of cytokinesis, effectively induced polyploidy. Polyploid mosaics rather than completion polyploids were found. The mosaics are likely to be produced due to the unique characteristics of cell division of the giant freshwater prawn eggs. Two nuclear divisions are normally completed producing 4 nuclei prior to the occurrence of cytokinesis. And the first and the second cytokineses occur simultaneously resulting in a production of 4cell embryos (Damrongphol et al. 1991b). Temperature shocks may disrupt only one of the cytokineses, thus, mosaics of diploid and polyploid are formed.

Direct chromosome number counts of the enlarged embryos are not presented. High chromosome number of decapods makes such counts rather improbable. Method of measuring the size of the erythrocytes has been used to identify the ploidy in fish (Benfey et al. 1984). Observation of the characteristics and the interspacing of the nuclei in the present study present a method for determining the mosaicism of the embryos. Mosaicism of the enlarged embryos is implication. The occurrence of the mosaics correlates with the occurrence of the enlarged embryos.

Mosaics have been described to occur in natural or by cytochalasin B induction in fish (Refstie 
et al. 1977, Allen and Stanley 1979). They appear physically normal but have degenerate gonads and show increased growth rate (Allen and Stanley 1978). The enlarged giant freshwater prawn embryos induced hold promise for further improvement in prawn aquaculture. The present study successfully induced enlarged embryos but still with relatively low levels and none of the enlarged embryos was able to hatch. Nevertheless, they developed normally. The temperature shocks may cause an accumulation of inhibitory protein(s) interfering hatching or may destroy enzyme(s) or protein(s) involved in the hatching process. Further investigation of the mechanisms of hatching is necessary in resolving this problem. An alternative polyploid induction with chemicals such as cytochalasin B may provide a less traumatic treatment to embryos.

\section{Acknowledgements}

The authors would like to thank Ms. Pensri Nopthamthorn for helping in preparation of the manuscript. This work was financially supported in part by Grant BRG 388001 from the Thailand Research Fund.

\section{References}

Allen Jr, S. K. and Stanley, J. G. 1978. Reproductive sterility in polyploid brook trout, Salvelinus fontinalis. Trans. Amer. Fish. Soc. 107: 473-478.

— and - 1979. Polyploid mosaics induced by cytochalasin B in Lanlocked Atlantic salmon Salmo salar. Trans. Amer. Fish. Soc. 108: 462-466.

Arai, K. and Wilkins, N. P. 1987. Triploidization of brown trout (Salmo trutla) by heat shocks. Aquaculture 64: 97-103.

Beaumont, A. R. and Contairis, M. S. 1988. Production of triploid embryos of Tapes semidecussatus by the use of cytochalasin B. Aquaculture 73: 37-42.

- and Fairbrother, I. E. 1991. Ploidy manipulation in molluscan shellfish a review. J. Shellfish Res. 10: 1-18.

Benfey, T. J., Sutterlin, A. M. and Thompson, R. J. 1984. Use of erythrocyte measurements to identify triploid salmonids. Can. J. Fish. Aquat. Sci. 41: 980-984.

Damrongphol, P., Eangchuan, N. and Poolsanguan, B. 1990. Simple in vitro culture of embryos of the giant freshwater prawn (Macrobrachium rosenbergii). J. Sci. Soc. Thailand 16: 17-24.

- - - and - 1991a. Spawning cycle and oocyte maturation in laboratory-maintained giant freshwater prawns (Macrobrachium rosenbergii). Aquaculture 95: 347-357.

- - - and - 1991b. Chromosome behavior upon fertilization in eggs of the giant freshwater prawn, Macrobrachium rosenbergii (de Man). Inv. Reprod. Dev. 19: 45-49.

Guo, X., Cooper, K., Hershberger, W. K. and Chew, K. K. 1992a. Genetic consequences of blocking polar body I with cytochalasin B in fertilized eggs of the Pacific oyster, Crassostrea gigas T.: I. Ploidy of resultant embryos. Biol. Bull. 183: 381-386.

- Hershberger, W. K., Cooper, K. and Chew, K. K. 1992b. Genetic consequences of blocking polar body I with cytochalasin B in fertilized eggs of the Pacific oyster, Crassostrea gigas T.: II. Segregation of chromosomes. Biol. Bull. 183: $387-393$.

Johnstone, R. 1985. Induction of triploidy in Atlantic salmon by heat shock. Aquaculture 49: 133-139.

Lemoine, H. L. and Smith, L. T. 1980. Polyploidy induced in brook trout by cold shock. Trans. Am. Fish. Soc. 109: $626-631$.

Lincoln, R. F. and Scott, A. P. 1983. Production of all-female triploid rainbow trout. Aquaculture 30: 375-380.

Quillet, E. and Panelay, P. J. 1986. Triploidy induction by thermal shocks in the Pacific oyster, Crassostrea gigas T. Aquaculture 57: 271-279.

Refstie, T. 1981. Tetraploid rainbow trout produced by cytochalasin B. Aquaculture 25: 51-58.

—, Vassvir, V. and Gjedrem, T. 1977. Induction of polyploidy in salmonids by cytochalasin B. Aquaculture 10: 65-74.

Wolters, W. R., Libey, G. S. and Chrisman, C. L. 1981. Induction of triploidy in channel catfish. Trans. Am. Fish. Soc. 110: 312-314.

Yamamoto, S. and Sugawara, Y. 1988. Induced triploidy in mussel, Mytilus edulis, by temperature shock. Aquaculture 72: 21-29. 